\title{
A DYNAMIC SIMULATION MODEL FOR ECONOMIC FEASIBILITY OF APARTMENT DEVELOPMENT PROJECTS
}

\author{
Kwangchae LEE (D), Seunghyun SON (D), Doyeong KIM (D), Sunkuk KIM \\ Department of Architectural Engineering, Kyung Hee University, Suwon, Republic of Korea
}

Received 08 September 2018; accepted 04 March 2019

\begin{abstract}
Many factors influence the success of apartment development projects, but it is difficult to quantitatively measure them. In terms of risk control, the five most direct influence factors are sales ratio, unit sale price, financial cost, land cost, and construction cost. These factors will vary during the project, from planning to land purchase to design to sale to construction, and the levels of these factors will also affect project performance. Therefore, it is necessary to dynamically forecast, control and monitor, and manage these factors in order to successfully implement apartment development projects. This study develops a dynamic simulation model to analyze the economic feasibility of apartment development projects. It draws a causal loop diagram of the aforementioned influence factors, develops a simulation model using system dynamics, and verifies the model with a case study of a 1,794-unit apartment development project. Using this simulation model, it is possible to quickly and easily simulate the economic effects of the risk factors that change throughout the project, analyze its economic feasibility, and develop a plan to reduce economic losses, if necessary. The simulation model can also identify the optimal conditions for project feasibility and develop a risk-control model for apartment development projects.
\end{abstract}

Keywords: apartment, development projects, economic feasibility, risk factors, system dynamics, simulation model.

\section{Introduction}

Numerous factors influence the success of apartment development projects (Rachmawati, Soemitro, Adi, \& Susilawati, 2018). Shi Ming and Chee Hian (2005) suggested that location, transportation, convenience facilities, educational environment, infrastructure, and relevant laws and regulations all influence the apartment sales ratio, determining whether apartment development projects will succeed or fail. Michael, Vicky, and Michael (2002) and Go, Hong, Song, and Park (2005) sought to determine project feasibility by analyzing location, surrounding areas, constructor brand preferences, and investment value, while Koo and Jung (2007) categorized risk factors largely into development location and market environment so as to analyze the feasibility of construction and development projects; the risk factors were further classified into 220 evaluation items, including qualitative elements.

However, it is difficult to clearly and quantitatively measure the relationship between risk factors and project feasibility, and virtually no studies have dealt with this subject. In particular, previous attempts did not properly reflect a dramatically changing project environment before, during, and after a project period. As a result, no clear, quantitative analysis of project feasibility has yet been performed (Ferreira \& Jalali, 2015). Moreover, the current methods do not really quantify the risks caused by a changing environment in an apartment development project (Kim, 2006). It is therefore necessary to determine which factors can best be used to make a full quantitative analysis of project feasibility, and establish a simulation model that reflects the dynamic relationship among them.

According to Park (2018), Won (2014), and Park, Kwon, Cho, and Paek (2008), the risk factors that directly impact the success or failure of a project include sales ratio, unit sale price, financial cost, land cost, and construction cost. These factors will, however, vary during the project cycle, from project planning to land purchase to design to sale to construction, and the levels of these factors will affect project performance (Park, Chu, Lee, \& Kim, 2009). Thus, it is necessary to dynamically forecast, control and monitor, and manage these factors in order to successfully implement apartment development projects. This study develops a dynamic simulation model to analyze the economic feasibility of apartment development projects.

${ }^{*}$ Corresponding author. E-mail: kimskuk@khu.ac.kr 


\section{Methodology}

In order to develop a dynamic simulation model for economic feasibility analysis of apartment development project, this study proceeds as shown in Figure 1. First, the causal loop diagram is created after analyzing the influences of economic risk factors of apartment development projects such as sales ratio, unit sale price, financial cost, land cost, and construction cost. Second, a simulation model for economic feasibility analysis is developed by the system dynamics method based on the generated causal loop diagram. Here, system dynamics is used to determine the economic effect of the risk factors over time. Third, the effectiveness of the developed simulation model is verified through a case application.

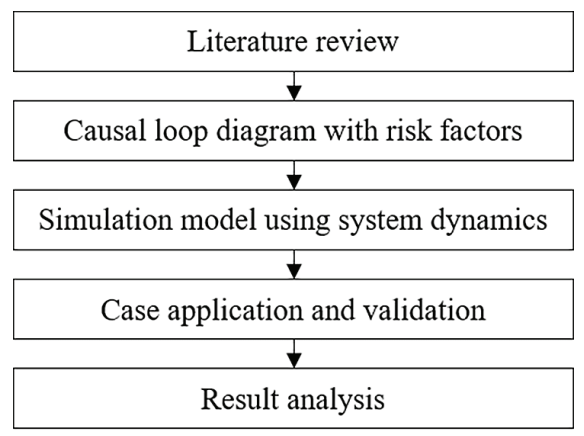

Figure 1. Methodology

The dynamic simulation model developed in this study will provide a new approach to easily and quickly simulate the economic effect of changing risk factors throughout an apartment development project. In practice, it can be used to analyze the economic feasibility of apartment development projects and to prepare strategies to reduce economic losses. In addition, it will be used to identify conditions for optimizing the feasibility of apartment development projects and to develop a risk management model.

\section{Preliminary study}

\subsection{Dynamic consideration of risk influence factors}

This section specifically illustrates the problems of existing project feasibility analysis methods by evaluating some preceding studies and suggesting a new direction for model development.

First, in selecting the risk factors in apartment development projects, most past studies included qualitative factors such as location, environment, and social and political factors, as well as quantitative factors that directly affect project profit and cost. For instance, Park, Sun, and Kim (2006) included educational environment, convenience facilities, status of the real estate market, and awareness of constructor brands, and analyzed the weight of each variable according to importance. Ball, Meen, and Nygaard (2010) also selected transportation and accessibility, surrounding area, apartment features, and neigh- borhood community as apartment purchasing determinants, analyzed them through interviews with experts, and measured the importance of each element.

However, those studies considered too many qualitative factors, causing confusion in analyzing actual project feasibility. They simply illustrated how much impact the qualitative factors would have on project performance and failed to clearly quantify the relationship between these factors and project performance. For this reason, it is impossible to practically and effectively apply those studies' results.

In contrast, this study addresses only the more qualitative, core risk factors in order to analyze project feasibility. In terms of risk control, Park (2018) and Won (2014) suggested that the most important qualitative factors are: sales ratio, unit sale price, financial cost, land cost, construction cost, and length of sale period, which reflect the actual prices, land values, and sales ratios of the surrounding area. Huh, Hwang, and Lee (2012) and Park et al. (2008) attempted to control risks qualitatively and rationally by defining land cost, construction cost, and financial cost as factors directly influencing overall project cost.

The discussed studies correctly listed the variables used to analyze project feasibility and economic feasibility, by confining the risk factors to the few that directly influence project profit. Similarly, this study defines five economic risk factors to analyze project feasibility: sales ratio, unit sale price, financial cost, land cost, and construction cost.

Also, most past studies of project feasibility for apartment development projects utilized statistical analysis methods such as time series, regression, and sensitivity analysis. For instance, Bae, Kim, Shin, and Cha (2017) performed regression analysis on an apartment development project case of 350 units in 127 apartment blocks in order to use apartment price determinants as a qualitative price index. Schniederjans, Hoffman, and Sirmans (1995) evaluated the characteristics of qualitative and quantitative factors that influence the apartment development process using the analytic hierarchy process (AHP), and established a project feasibility analysis model through time series analysis. Yoon, Yun, and Paek (2006) defined risk factors requiring special attention through sensitivity analysis in order to forecast the cash flow of real estate development projects.

However, Choi (2002) suggested that data-based time series and regression analysis are static analysis methods and thus cannot dynamically reflect various changes that may occur over time, since static analysis methods estimate numeric data corresponding to analysis-related conditions only at the time of analysis. According to Choi, Park, Lee, and Hwang (2017), when apartment development projects require several years to complete, significant changes may occur in the conditions being analyzed during the project timeline, invalidating the effectiveness of a plan that was developed based on initial analysis results. In other words, the existing analysis models of project feasibility cannot reflect a dynamically changing environ- 
ment over a project timeline, meaning they do not consider time as an important variable.

To address this problem, Al-Bahar and Crandall (1990) and Mills (2001) stated that system dynamics need to be adopted if the systems and profit structure, as well as the cash flow, are as complex as those of building development projects. System dynamics can identify the flows of profit and cost that occur due to the feedback structure of various risk factors over a long period of time, and thereby evaluate the pattern of changes in the economic feasibility of projects (Mills, 2001).

Accordingly, this study establishes a dynamic simulation model of five economic risk factors (sales ratio, unit sale price, financial cost, land cost, and construction cost). Using this model, it is possible to easily and quickly simulate the economic effects of the risk factors that change throughout a project, and develop a plan to analyze its economic feasibility and reduce economic losses.

\subsection{Dynamic simulation model concept}

The simulation model developed in this study can be used to determine project profit over time using multiple cases by considering the dynamic relationship among five economic risk factors: sales ratio, unit sale price, financial cost, land cost, and construction cost.

To establish a dynamic simulation model, a generation model is first established, which includes a calculation formula based on the mathematical definition of each factor. Then a simulation model is developed based on the generation model. To this end, the concept of a generation model for establishing a dynamic model, and a simulation model to be developed based on the generation model, will be defined here.

As shown in Figure 2, this generation model measures project profit by calculating income and cost using five economic risk factors (sales ratio, unit sale price, financial cost, land cost, and construction cost) (Chen, O’Brien, \& Herbsman, 2005). The five economic risk factors are defined as $f_{1}, f_{2}, \cdots, f_{5}$ and formulas to calculate income and cost are drawn. Thus, the relationship between project profit and each factor is mathematically connected.

A generation model is designed to mathematically define the relationship between individual influence factors and project goals, while a simulation model is established based on the generation model to simulate multiple cases (Park, 2018). Further development of the generation mod-

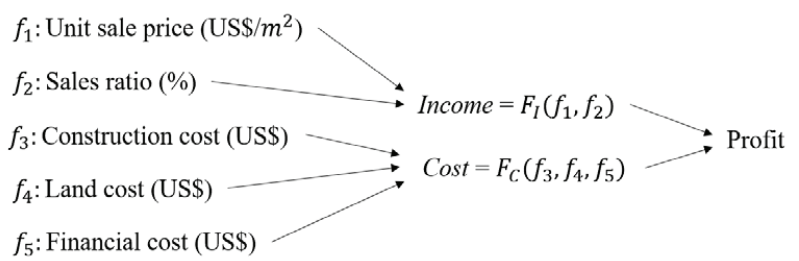

Figure 2. Generation model concept

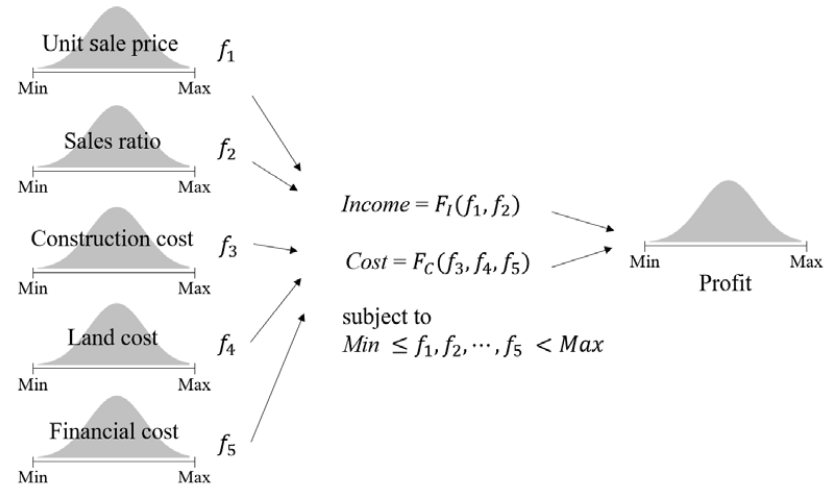

Figure 3. Simulation model concept

el is described in detail in Section 4 using a mathematical model of each factor.

Once a generation model is developed, a simulation model can be established based upon it. As shown in Figure 3, the five economic risk factors are mathematically defined as probabilistic random variables for the five mathematically defined economic risk factors are created, and $n$ values of income and cost are calculated for the project; thus, multiple cases of project profit are produced. The upper and lower control limits of each factor to achieve the targeted profit can be set using the multiple cases resulting from the simulation. The process and details of establishing the model building and management ranges will be described in detail in Section 4 .

\section{Causal loop diagram}

In this section, the interrelationships among economic risk factors are analyzed and a causal loop diagram is developed. As shown in Figure 4, the economic feasibility of apartment development projects is determined by project profit, which is calculated using project costs, financial cost, sales income, and financial income (Chan \& $\mathrm{Au}$,

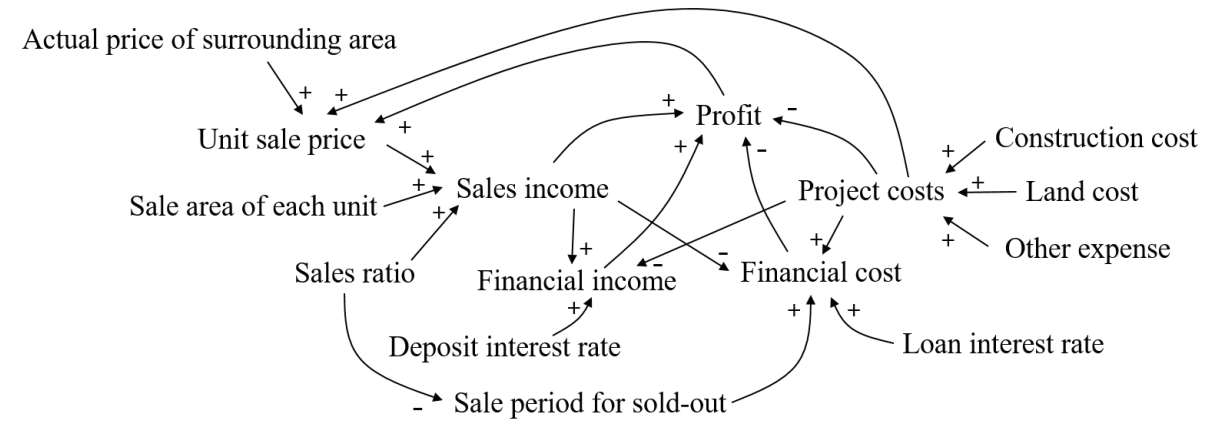

Figure 4. Causal loop diagram 
2009). For the calculation formula of project profit, see Formula (9) in Section 4.4.

Sales income is calculated using sales income, unit sale price, sale area of each unit, and sales ratio as shown in Figure 4; any change in these factors affects the level of sales income (Tan, Shen, \& Langston, 2010). Sales income and its related influence factors are calculated in Formulas (1) to (3) in Section 4.1. As shown in Figure 4, the deposit interest income for surplus funds should be added when calculating $F_{\mathrm{I}}$, and costs other than $f_{3}, f_{4}$, and $f_{5}$, such as expenses for showroom building, advertising, and approval and licensing, should be reflected when calculating $F_{\mathrm{C}}$ (Jeong, 2001).

Project costs are also calculated using land cost, construction cost, and other expenses, and any change in these factors affects the level of project costs (Isaac \& Navon, 2009). Project costs and their related influence factors are calculated in Formulas (4) to (7) in Section 4.2.

An example of a causal relationship among the factors shown in Figure 4 is land cost, which often comprises a very large portion of total project costs, especially for development sites closer to cities (Adair, McGreal, Smyth, Cooper, \& Ryley, 2000). If the land cost is higher than expected, the unit sale price must go up to meet the targeted project profit. This consequently affects the sales ratio and financial cost, which determine the success or failure of the project (Zavadskas, Turskis, \& Tamošaitiene, 2010). Therefore, it is necessary to plan and determine the total land cost and the maximum limit of the individual land cost by considering total project costs.

According to the many studies (Huh, Hwang, \& Lee, 2012; Park, Sun, \& Kim, 2006; Ball, Meen, \& Nygaard, 2010) and actual development projects performed so far, the unit sale price has a strong correlation with the market price neighboring apartments, ie, the actual price of the surrounding area. The biggest risk factor before a sale is the unit sale price (Albert, Grenier, Denis, \& Rousseau, 2008). Here, unit sale price is determined by considering the project costs and profit as shown in Figure 4. It can be changed by comparing and reviewing the actual unit prices in the surrounding area when preparing for the project. If the unit sale price is set higher than the actual prices in the surrounding area, the sales ratio will be low, making it difficult to secure enough funding and causing a setback in project progress. If the unit sale price is set lower than of those in the surrounding area, it will be impossible to meet the profit forecasts (Seo, 2016). In other words, houses sold at unit sale prices lower than the market price are sold out quickly, but they are perceived as having lost the opportunity to raise project profit by selling more expensive. As a result, when the unit sale price is determined, the level of reflection of the actual price of the surrounding area becomes a key factor in determining the project profit. Therefore, the financial benefits from the project must be verified by closely reviewing the land cost, licensing charges, and a variety of other payments to determine the unit sale price; the control range of the unit sale price can be adjusted to achieve the targeted profit.

After the unit sale price is determined and sales begin, the next biggest influence factor is the sales ratio. If the initial sales ratio is high, sufficient funding for the project will be secured (Caldera \& Johansson, 2013). In other words, the project financing (PF) costs and other financial costs can be reimbursed early to increase profit. If the sales ratio is low, the flow of funds will become unpredictable and the constructor may fail to make repayments, which is a major cause of project failure (Warszawski, 2003). For this reason, it is necessary to forecast the flow of funds and set the control range of the sales ratio through the simulation, thereby determining whether to change the unit sale price, take the hit, or withdraw from the project.

Thus, what determines changes in sales income or project costs are the ranges of the various related influence factors (the variables). It all comes down to project profit. Therefore, the main purpose to the model developed in this study is to maintain sufficient project profit by adjusting the sale income and/or the project costs within the variation ranges of the influence factors.

\section{Dynamic simulation model}

This section shows how to establish a dynamic simulation model based on the casual loop diagram drawn in the previous section. It is intended to dynamically analyze the economic risk factors related to profit over time (Nasirzadeh, Afshar, Khanzadi, \& Howick, 2008). The proposed model works from $t_{0}$ to $t_{3}$ as shown in Figure 5 .

$t_{0}$ is the phase of carrying out the economic feasibility study of the project on hand. If the feasibility of the project is confirmed by the proposed dynamic simulation model at this stage, the project is started. The purchase of land is followed within the range obtained by the simulation result, and the preliminary construction contract is executed.

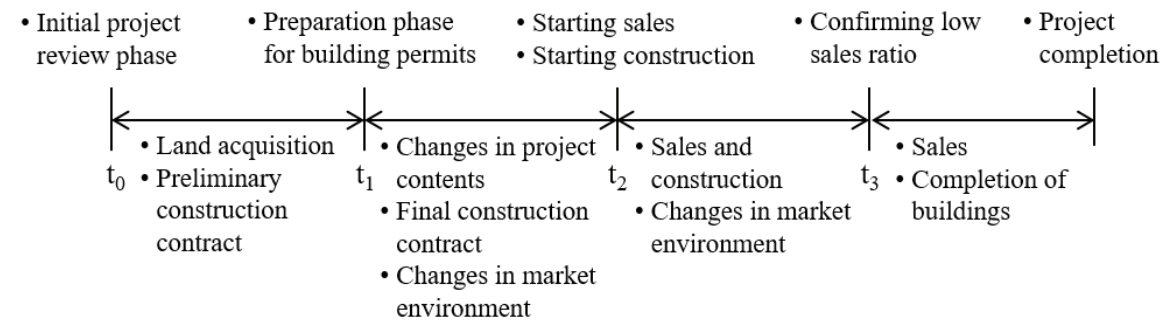

Figure 5. Simulation phases of economic feasibility 
$t_{1}$ is the phase of acquiring a building permit after completing the design of the buildings. Project contents such as number of buildings and housing units, building heights, building coverage and volume can be changed from the initial plan. The final construction contract is made according to the result of this phase, and it affects the project profit. Therefore, the sale price should be reviewed again by reflecting the result and the change of economic situation by the proposed simulation model.

$t_{2}$ is the phase to start the sale, and construction is started at the same time. Before the sale, the final sale price should be finally determined by the proposed model after continuously monitoring the market situation up to $t_{2}$.

$t_{3}$ is the time when low sales ratio has been confirmed. For reference, $t_{3}$ does not occur if the sale is completed at $t_{2}$ or if the sale proceeds at the expected sales ratio before $t_{3}$. At this phase, land and construction cost cannot be changed because they are already acquired and signed. And the financial costs will increase sharply because the progress payment for the apartment buildings should be paid continuously. In other words, unlike individual housing units, which are built by order, residential buildings should be constructed entirely even if only a part of all housing units are sold.

In this case, the sales income is not sufficient enough to cover the construction cost, and the interest cost of project loan is sharply increased due to the rapid increase of it. If this situation gets worse as time goes by, the project will default. In order to prevent such a situation, the residual houses must be sold again after reducing the unit sale price even if profit is minimized. The bold line in Figure 6 shows the feedback routine that simulates the sales income and project profit after reducing the unit sale price.

Such a feedback structure basically aims that the financial cost, which is increased by the unsold housing units, becomes smaller than the adjusted target profit. New strategies should be established to minimize deficits if the sales ratio is consistently low after $t_{3}$. This feedback structure is reflected in the dynamic model of this study. This case will be explained in more detail in Chapter 5 Case Analysis. In this way, the dynamic model of this study can be simulated according to the business stage $\left(t_{0}-t_{3}\right)$, and it can be operated flexibly according to the decision of the developer.

\subsection{Income model}

Because existing feasibility analyses do not take time into account, they are unable to reflect profit or cost that oc-

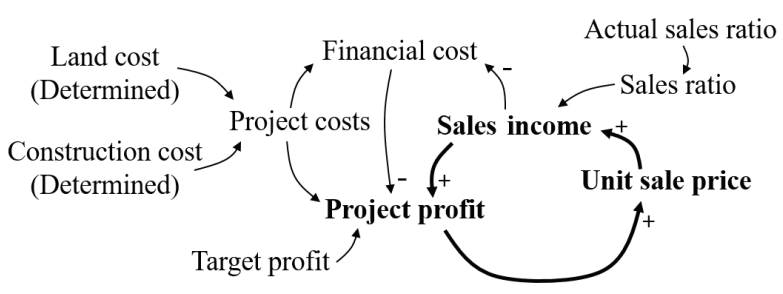

Figure 6. Causal loop diagram focused on $t_{3}$ curs over an extended period of time (Yuan, Shen, Hao, \& Lu, 2011). However, the model developed in this study is designed to calculate sales income over time, and can show the change in monthly sales income caused by changes in sales ratio and unit sale price, which are economic risk factors (Figure 7).

The total sale income from apartments $\left(S_{\text {total }}\right)$ is calculated by Formula (1); it is estimated as the sum of the monthly sale income. Monthly sale income is automatically calculated from the unit sale price per apartment type $\left(U P_{\text {type }}\right)$, the sale area of each unit per apartment type $\left(U A_{\text {type }_{i}}\right)$, and the number of units per apartment type $\left(N_{i}\right)$. Here, unit sale price must reflect the actual prices in the surrounding area, including neighboring housing prices and locations. The number of months from project commencement to completion $(j)$ is set by a parameter. Accordingly, this model can project income that occurs over time.

$$
S_{\text {total }}=\sum_{i=1}^{1} \sum_{j=1}^{m} U P_{\text {type }} \times U A_{\text {type }} \times N_{i} \times f\left(x_{i j}\right) .
$$

The total sales ratio $\left(R_{\text {type }_{i}}\right)$ is the sum of the monthly sales ratio $\left(x_{i j}\right)$ from the start of the sales period until the project is completed, as shown in Formula (2). Here, $\left(R_{\text {type }}\right)$ does not need to exceed 1 , and the sales period $(j)$ is limited to the time from project commencement to completion.

$$
\begin{aligned}
& R_{\text {type }_{i}}=\sum_{j=1}^{n} f\left(x_{i j}\right)=x_{i 1}+x_{i 2}+\ldots+x_{i j}+\ldots+x_{i n} ; \\
& f\left(x_{i j}\right)=\frac{1}{\sigma \sqrt{2 \pi}} \exp \left(-\frac{\left(x_{i j}-\mu\right)^{2}}{2 \sigma^{2}}\right)
\end{aligned}
$$

Here, $\mu$ : Average, $\sigma^{2}$ : Distribution,

$$
\text { Subject to } 0 \leq x_{i n} \leq 100-\sum_{j=1}^{n-1} x_{i j} \text {. }
$$

This income model can show the change in final project profit by linking it to a cost model and a financial model. This allows for setting the upper and lower control limits of the unit sale price and the sales ratio, which are

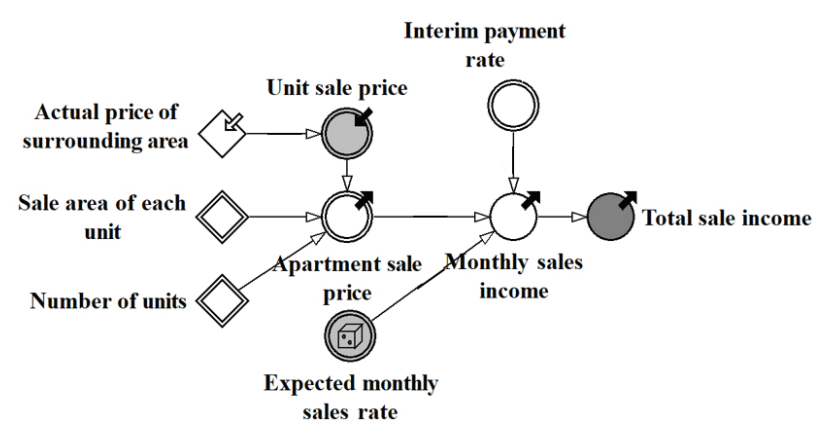

Figure 7. Income model 
the major influence factors, in order to review the feasibility and control the risk at each stage of the project.

\subsection{Cost model}

The cost model developed in this study is designed to produce monthly costs by entering construction costs, land cost, and other expenses as shown in Figure 8.

The total project cost $\left(C_{\text {total }}\right)$ is calculated as the sum of monthly construction cost $\left(C C_{j}\right)$, monthly land cost $\left(C L_{j}\right)$, and other expenses $\left(C E_{j}\right)$, as shown in Formula (4):

$$
C_{\text {total }}=\sum_{j=1}^{n}\left(C C_{j}+C L_{j}+C E_{j}\right) \text {. }
$$

Construction cost $\left(C C_{j}\right)$ is calculated as the sum of direct construction cost $\left(C_{\text {dire }}\right)$, to be input on a monthly basis, and indirect construction cost $\left(C_{\text {indi }}\right.$ ), as shown in Formula (5):

$$
C C_{j}=\sum_{j=1}^{n}\left(C_{\text {dire }_{j}}+C_{\text {indi }_{j}}\right) .
$$

The cost model calculates land cost $\left(C L_{j}\right)$ by multiplying land cost per each lot $\left(P L_{i}\right)$, land area per each lot $\left(A L_{i}\right)$, and land cost rates $\left(R L_{j}\right)$ during the period from project commencement until land acquisition, as shown in Formula (6):

$$
C L_{j}=\sum_{i=1}^{l} \sum_{j=1}^{n}\left(P L_{i} \times A L_{i} \times R L_{j}\right) .
$$

Other expenses $\left(C E_{j}\right)$ are calculated as the sum of outsourcing service cost $\left(C_{o s_{j}}\right)$, sale expenses $\left(E_{p s_{j}}\right)$, and other expenses $\left(E_{o t_{j}}\right)$, as shown in Formula (7):

$$
C E_{j}=\sum_{j=1}^{n}\left(C_{o s_{j}}+E_{p s_{j}}+E_{o t_{j}}\right) .
$$

Here, the outsourcing service cost includes design fees, inspection fees, and survey fees. Sale expenses include all expenses related to sale, including advertising costs, model house $(\mathrm{M} / \mathrm{H})$ site rent, $\mathrm{M} / \mathrm{H}$ building cost, $\mathrm{M} / \mathrm{H}$ operation cost, and sale agency fees. Other expenses include development shares, preservation registration fees, commission on sale guarantees, and reserved funds. Each cost item is calculated for each period according to a payment rate,

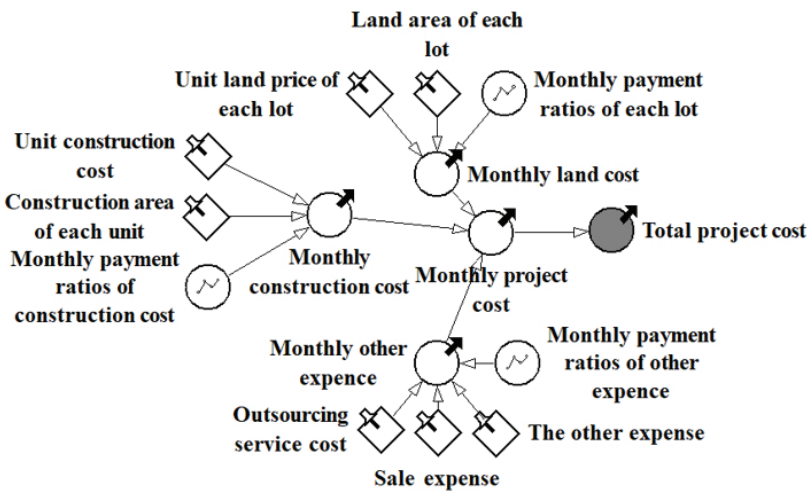

Figure 8. Cost model and then linked to a financial cost model to produce total spending.

The cost model can show the change in final project profit by linking it to an income model and a financial model. This allows for setting the upper and lower control limits of construction cost and land cost, which are the major influence factors, to review the feasibility and control the risk at each stage of the project.

\subsection{Financial cost model}

A financial cost model incorporates monthly financial income and monthly financial cost, as shown in Figure 9. Financial cost and income are calculated according to monthly gain and loss based on monthly sale income $\left(S_{j}\right)$ and monthly spending $\left(C_{j}\right)$. Here, the sale period is very important in calculating financial cost.

Most apartment development project failures are attributed to inadequately forecasting the sale period (Lee, Lee, \& Kim, 2016), because extended sale periods lead to enormous expenses (Woo \& Lee, 2005). Therefore, the model developed in this study is designed to project financial costs and income that occur as the project goes on, by setting the number of months from project commencement to completion as a parameter. The calculation is shown in Formula (8):

$C_{F}=\sum_{j=1}^{n}\left(S_{j}-C_{j}\right) \times k$,

$\left(\right.$ Here, $\mathrm{k}:\left\{\begin{array}{l}\text { if } S_{j}-C_{j} \geq 0 \text {, deposit interest ratesis applied } \\ \text { if } S_{j}-C_{j}<0 \text {, loaninterest ratesis applied }\end{array}\right)$.

Here, financial cost $\left(C_{F}\right)$ occurs when the amount of monthly income $\left(S_{j}\right)$ is greater than or equal to the amount of monthly cost $\left(C_{j}\right)$, and it is calculated by applying deposit interest rates. This calculates the total income as the sum of sale income and financial income by linking it to an income model.

Financial cost also occurs when the amount of monthly income $\left(S_{j}\right)$ is less than the amount of monthly cost $\left(C_{j}\right)$, and it is calculated by applying loan interest rates. This is designed to calculate total spending as the sum of project cost and financial cost by linking it to a cost model. In particular, this model can show the maximum financial cost arising from the calculated monthly financial cost, and whether one should raise funds in a timely manner; this will help determine the success of the project.

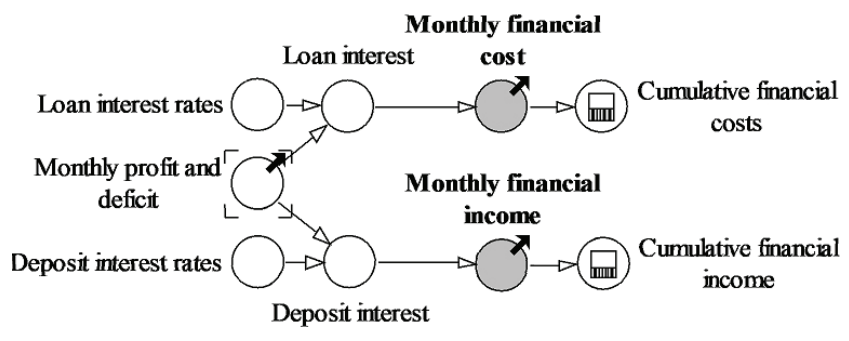

Figure 9. Financial cost and income model 


\subsection{Integrated simulation model}

One existing approach to analyzing project feasibility involves simply listing income and costs one by one and converting them into monthly values, without considering the complex interactions of the various factors which affect income and cost (Han, Jang, Lee, \& Kim, 2007). In contrast, the integrated simulation model developed in this study simulates project profit by considering causal relationships and linking them to an income model, a cost model, and a financial cost model, as shown in Figure 10.

Project profit $\left(P_{\text {Project }}\right)$ is calculated by subtracting the sum of monthly cost $\left(C_{j}\right)$ and monthly financial cost $\left(F C_{j}\right)$ from the sum of monthly income $\left(S_{j}\right)$, and monthly financial income $\left(F I_{j}\right)$ which occur during the project, as shown in Formula (9). Here, the change in project profit is displayed by changing the factors applied to the income and cost models. This allows for project feasibility analysis and risk control against any changes in the market and project environment.

$$
P_{\text {project }}=\sum_{j=1}^{n}\left\{\left(S_{j}+F I_{j}\right)-\left(C_{j}+F C_{j}\right)\right\} .
$$

Accordingly, it is possible to simulate project profit by changing the sales ratio, unit sale price, construction cost, land cost, and financial cost, the economic risk factors that will directly influence the success of projects. This allows for setting the upper and lower control limits of each factor to achieve the targeted profit, review feasibility, and control risk at each stage of the project.

In Figure 10, the unit sale price and the expected sales ratio should be linked dynamically, and mathematical formulas or logics should be provided to estimate the effect of the unit price on sales. However, to date, there has been no quantitative formulas or logics of the effect. A lot of accumulated data and efforts are needed to solve this issue. Therefore, in the proposed model, the sales ratio should be determined by the experts' judgment of building project development considering the sales ratio result of similar projects already performed in the neighboring region and various market conditions until the dynamic relations to clearly explain the effect of the unit price on sales are facilitated.

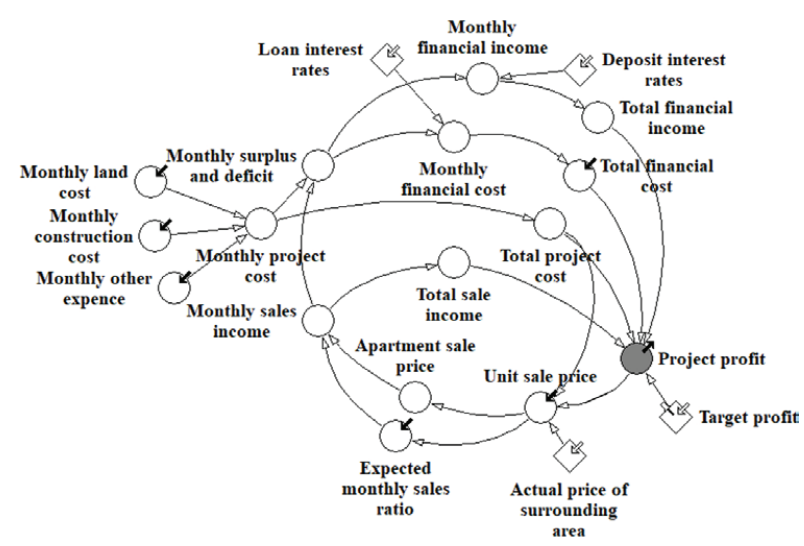

Figure 10. Integrated simulation model

\section{Case application and discussion}

This section verifies the effectiveness of the simulation model through case application. The model of this study can be simulated at each phase $\left(t_{0}-t_{3}\right)$. In phase $t_{0}-t_{2}$, the developer sets a control limit for each factor so that the targeted profit can be achieved using the model. In this case, $t_{3}$ does not occur if the sale is completed at $t_{2}$ or if the sale proceeds at the expected sales ratio before $t_{3}$. If, $t_{3}$ is occurred, in phase $t_{3}$, the developer adjusts the unit sale price to simulate the financial cost and profit according to the change in the residual sales ratio.

Table 1 shows an overview of a case project to supply 1,794 apartment units, to be built with 31 stories aboveground and 2 basement levels. The apartment project consists of 442 units of $75 \mathrm{~m}^{2}, 1,192$ units of $102 \mathrm{~m}^{2}$, and 160 units of $126 \mathrm{~m}^{2}$.

Table 1. Brief description of a case project

\begin{tabular}{|l|l|}
\hline \multicolumn{1}{|c|}{ Description } & \multicolumn{1}{c|}{ Contents } \\
\hline Project title & HID apartment development \\
\hline Location & Goyang, Gyeonggi, Korea \\
\hline Site area & $84,971 \mathrm{~m}^{2}$ \\
\hline TFA/Building area & $277,525 \mathrm{~m}^{2} / 11,894 \mathrm{~m}^{2}$ \\
\hline Volume/Building coverage & $229.09 \% / 14.00 \%$ \\
\hline No. of units & 1,794 units $(3$ types $)$ \\
\hline Construction period & 28 months \\
\hline
\end{tabular}

The case project acquired land at $1,125 \mathrm{USD} / \mathrm{m}^{2}$ and sold it at 3,090 USD $/ \mathrm{m}^{2}$ after completing the licensing procedure. The case project expects the initial threemonth sales ratio to exceed $60 \%$. However, the actual sales ratio remained at $30 \%$. When reviewing the initial project feasibility, the rate of return was expected to be around 9.3\% (about 56,742,620 USD). But, when the apartments were built, the poor sales ratio resulted in unsold new apartment stock and failure to achieve the targeted rate of return.

A general project feasibility review cannot forecast dynamic changes in profit caused by variations in sales ratios and interest rates (Li \& Liao, 2007). In other words, it is difficult to respond to risks before confirming the final results of a project (Schieg, 2008). However, the model developed in this study can perform dynamic analysis over time, so in the event of a poor sales ratio, for example, it can simulate the project profit by changing the factors which influence project income.

\section{(1) Initial sales strategy}

The initial values of the risk factors were entered as shown in Table 2, with $3,090 \mathrm{USD} / \mathrm{m}^{2}$ in unit sale price, $1,125 \mathrm{USD} / \mathrm{m}^{2}$ in land cost, $968 \mathrm{USD} / \mathrm{m}^{2}$ in construction cost, and $165 \mathrm{USD} / \mathrm{m}^{2}$ in other expenses, including outsourcing service costs, sale expenses, and other expenses. The project period was 46 months, and $4.1 \%$ loan interest rates and $2.9 \%$ deposit interest rates were applied. 
Table 2. Initial values of risk factors

\begin{tabular}{|l|c|c|}
\hline \multicolumn{1}{|c|}{ Item } & Unit & Initial value \\
\hline Unit sale price & $\mathrm{USD} / \mathrm{m}^{2}$ & 3,090 \\
\hline Land cost & $\mathrm{USD} / \mathrm{m}^{2}$ & 1,125 \\
\hline Construction cost & $\mathrm{USD} / \mathrm{m}^{2}$ & 968 \\
\hline Other costs & $\mathrm{USD} / \mathrm{m}^{2}$ & 165 \\
\hline Loan interest rates & $\%$ & 4.1 \\
\hline Deposit interest rates & $\%$ & 2.9 \\
\hline Project period & Months & 46 \\
\hline
\end{tabular}

Note: KRW 1,127.90 = USD1.00 as of 2018/08/03 (Bank of Korea).

These values were applied to the dynamic simulation model in Figure 10. Assuming that each risk had a standard deviation of 0.1, as shown in Figure 11, random variables with normal distributions were created. These were used to determine the changes in project profit.

Simulations were performed 100,000 times to forecast the project profit, as graphed in Figure 11 (a)-(d) and summarized in Table 3. As a result, the average, maxi- mum, and minimum unit sale prices were: $3,091 \mathrm{USD} / \mathrm{m}^{2}$, $4,326 \mathrm{USD} / \mathrm{m}^{2}$, and $1,707 \mathrm{USD} / \mathrm{m}^{2}$ respectively as shown in Figure 11 (a). The average, maximum, and minimum land cost were: $1,125 \mathrm{USD} / \mathrm{m}^{2}, 1,576 \mathrm{USD} / \mathrm{m}^{2}$, and $664 \mathrm{USD} / \mathrm{m}^{2}$ respectively as shown in Figure 11 (b). The average, maximum, and minimum construction costs were $968 \mathrm{USD} / \mathrm{m}^{2}, 1,384 \mathrm{USD} / \mathrm{m}^{2}$, and $550 \mathrm{USD} / \mathrm{m}^{2}$ respectively as shown in Figure 11 (c). Depending on the variation in risk factors, the average, maximum, and minimum project profits were: 56,737,158 USD, 200,255,758 USD, and 82,461,955 USD, respectively, as shown in Figure 11 (d).

If, for instance, a developer sets the targeted rate of return to $9.3 \%-10 \%$, the unit sale price, land cost, and construction cost need to be set within the ranges of $2,174-4,067 \mathrm{USD} / \mathrm{m}^{2}, 728-1,526 \mathrm{USD} / \mathrm{m}^{2}$, and $787-$ $1,140 \mathrm{USD} / \mathrm{m}^{2}$, respectively. If they are beyond these control limits, a plan to minimize risks, such as a change in the targeted rate of return, needs to be developed.

In this way, the dynamic simulation model developed in this study can forecast a project's rate of return accord-

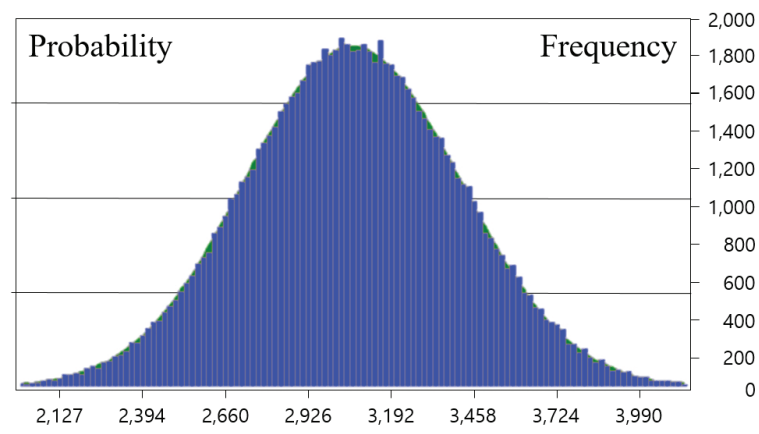

(a) Unit sale price $\left(\mathrm{USD} / \mathrm{m}^{2}\right)$

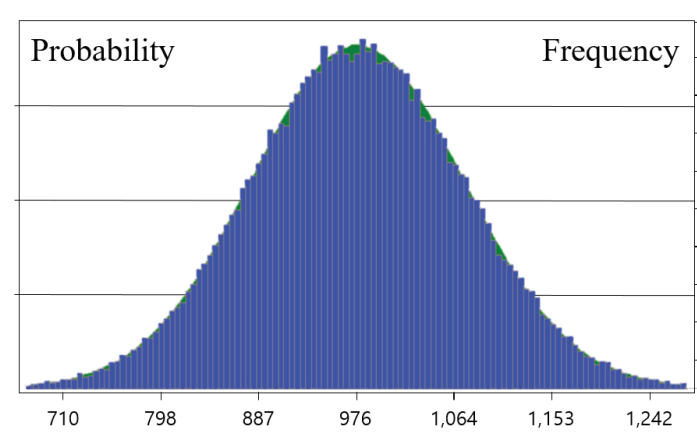

(c) Construction cost (USD $\left./ \mathrm{m}^{2}\right)$

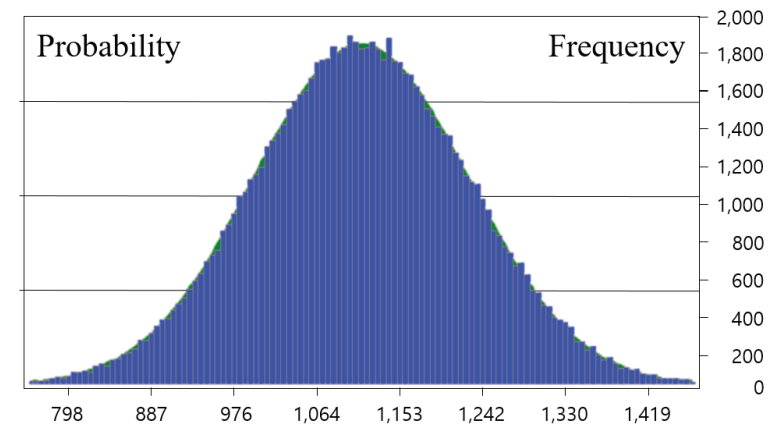

(b) Land cost (USD $\left./ \mathrm{m}^{2}\right)$

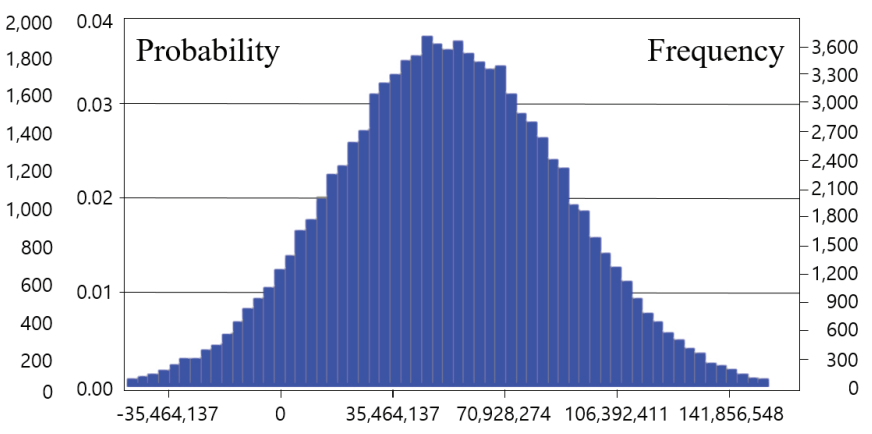

(d) Project profit (USD)

Figure 11. Random variable generation by factors and changes in project profit

Table 3. Results of simulation at the initial project review phase

\begin{tabular}{|l|c|c|c|c|c|}
\hline \multicolumn{1}{|c|}{ Description } & Unit & Times & Average & Maximum & Minimum \\
\hline Unit sale price & $\mathrm{USD} / \mathrm{m}^{2}$ & 100,000 & 3,091 & 4,326 & 1,707 \\
\hline Land cost & $\mathrm{USD} / \mathrm{m}^{2}$ & 100,000 & 1,125 & 1,576 & 664 \\
\hline Construction cost & $\mathrm{USD} / \mathrm{m}^{2}$ & 100,000 & 968 & 1,384 & 550 \\
\hline Profit & $\mathrm{USD}$ & 100,000 & $56,737,158$ & $200,255,758$ & $-82,461,955$ \\
\hline
\end{tabular}

Note: KRW 1,127.90 = USD1.00 as of 2018/08/03 (Bank of Korea). 
Table 4. Setting the control limits

\begin{tabular}{|c|c|c|c|c|c|}
\hline \multirow[t]{2}{*}{ Trial value } & \multirow{2}{*}{$\begin{array}{c}\text { Earnings rate } \\
(\%)\end{array}$} & \multirow{2}{*}{$\begin{array}{l}\text { Profit } \\
\text { (USD) }\end{array}$} & \multicolumn{3}{|c|}{$\mathrm{USD} / \mathrm{m}^{2}$} \\
\hline & & & Unit sale price & Land cost & Construction cost \\
\hline 1 & -14.2 & $-82,461,955$ & 2,841 & 1,440 & 1,305 \\
\hline 2 & -12.3 & $-73,456,896$ & 2,676 & 1,412 & 1,252 \\
\hline$\cdots$ & $\cdots$ & $\cdots$ & $\cdots$ & $\cdots$ & $\cdots$ \\
\hline 49,875 & 9.3 & $57,651,200$ & 3,393 & 1,131 & 999 \\
\hline 49,876 & 9.3 & $57,155,902$ & 3,244 & 1,197 & 954 \\
\hline$\cdots$ & $\cdots$ & $\cdots$ & $\cdots$ & $\cdots$ & $\cdots$ \\
\hline 99,999 & 26.7 & $183,084,398$ & 3,568 & 927 & 664 \\
\hline 100,000 & 29.2 & $200,255,758$ & 3,501 & 1,052 & 603 \\
\hline
\end{tabular}

Note: KRW 1,127.90 = USD1.00 as of 2018/08/03 (Bank of Korea).

ing to changes in its risk factors. This model also allows a developer, through simulation, to determine the upper and lower control limits of each factor to achieve the targeted project profit. If the project is operated within the control limits, the targeted profit can be achieved.

\section{(2) Re-simulation after confirming low sales ratio at $t_{3}$}

For example, the actual initial 3-month sales ratio of the case project is $30 \%(12 \%, 10 \%, 8 \%)$. This is half of the sales ratio of $60 \%$ expected at the initial project review phase $\left(t_{0}\right)$. Due to the low sales ratio, financial costs have increased as the sales period for unsold housing units takes long time. As a result, the target profit rate of $9.3 \%$ was not achieved and failed in business aspect.

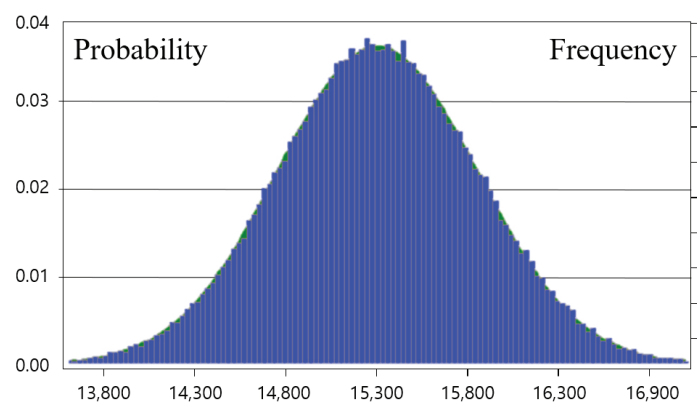

(a) Financial cost (1,000 USD)
Therefore, this study assumes that the developer adjusts the original unit sale price, $3,090 \mathrm{USD} / \mathrm{m}^{2}$, to $2,960 \mathrm{USD} / \mathrm{m}^{2}$ at $\mathrm{t}_{3}$, and simulates again the financial cost and the business profit due to the change of the residual sales ratio. Table 5 and Figure 12 shows the results. In this simulation, the monthly sales ratio is set to a normal distribution. The average and standard deviation reflect the actual sales data after $t_{2}$. Here, the constraint of normal distribution is subject to the minimum value of $0 \%$ and the maximum value, the residual sales ratio at the time of re-simulation such as $70 \%$ in this case.

As a result of simulating the residual sales ratio 1,000 times as shown in Table 5, the average, maximum and minimum financial costs are 14,087,000 USD, 16,915,000 USD and 13,708,000 USD, respectively. And

Figure 12. Simulation result at $t_{3}$

Table 5. Results of simulation at $t_{3}$ (Unit: 1,000 USD)

\begin{tabular}{|c|c|c|c|c|c|c|c|c|c|c|c|c|c|}
\hline $\begin{array}{l}\text { Trial } \\
\text { value }\end{array}$ & $\mathrm{M}+4$ & $\mathrm{M}+5$ & $M+6$ & $\mathrm{M}+7$ & $\mathrm{M}+8$ & $\mathrm{M}+9$ & $\mathrm{M}+10$ & $M+11$ & $\mathrm{M}+12$ & $M+13$ & Total & $\begin{array}{c}\text { Financial } \\
\text { cost }\end{array}$ & Profit \\
\hline 1 & $7 \%$ & $6 \%$ & $2 \%$ & $6 \%$ & $6 \%$ & $11 \%$ & $2 \%$ & $6 \%$ & $6 \%$ & $17 \%$ & $100 \%$ & 16,915 & 23,933 \\
\hline 2 & $7 \%$ & $10 \%$ & $7 \%$ & $4 \%$ & $4 \%$ & $4 \%$ & $10 \%$ & $3 \%$ & $8 \%$ & $12 \%$ & $100 \%$ & 16,082 & 34,216 \\
\hline 3 & $7 \%$ & $7 \%$ & $7 \%$ & $6 \%$ & $10 \%$ & $7 \%$ & $5 \%$ & $7 \%$ & $2 \%$ & $10 \%$ & $100 \%$ & 15,734 & 37,904 \\
\hline$\ldots$ & $\ldots$ & $\ldots$ & $\ldots$ & $\ldots$ & $\ldots$ & $\ldots$ & $\ldots$ & $\ldots$ & $\ldots$ & $\ldots$ & $\ldots$ & $\ldots$ & $\ldots$ \\
\hline 998 & $13 \%$ & $15 \%$ & $12 \%$ & $14 \%$ & $14 \%$ & $1 \%$ & $1 \%$ & $0 \%$ & $0 \%$ & $0 \%$ & $100 \%$ & 13,750 & 58,115 \\
\hline 999 & $13 \%$ & $14 \%$ & $15 \%$ & $13 \%$ & $13 \%$ & $1 \%$ & $0 \%$ & $0 \%$ & $0 \%$ & $0 \%$ & $100 \%$ & 13,732 & 58,135 \\
\hline 1000 & $15 \%$ & $13 \%$ & $16 \%$ & $17 \%$ & $9 \%$ & $0 \%$ & $0 \%$ & $0 \%$ & $0 \%$ & $0 \%$ & $100 \%$ & 13,708 & 58,152 \\
\hline
\end{tabular}

Note: $1,127.90$ Won $=1$ USD as of 2018/08/03 (Bank of Korea). 
the average, maximum and minimum project profit are 41,042,000 USD, 58,152,000 USD and 23,933,000 USD, respectively. The sales should be completed within 5 months in order to achieve maximum profit, and the sales strategy should be set up to achieve 15\%,13\%,16\%, 17\% and 9\% sequentially. If the actual sale results for the next month fail to achieve the expected sale ratio, a new strategy should be established by adjusting the target profit again. In this way, the simulation is repeated according to the result over time by the model of this study.

As described in Section 4, the mathematical algorithms of the dynamic simulation model proposed in this paper logically correspond to the risks that arise as the project business progresses. In particular, the model is facilitated to feedback dynamically as shown in Figure 6 if the low sales ratio is confirmed at $t_{3}$ in Figure 5, which is the most important point of business failure. And, in case of such a situation, a strategic countermeasure was simulated through the case study. In other words, the dynamic model presented in this study is logically responding to the situation, and the validity of the proposed model is verified through the case study.

However, even if the validity of the model has been verified, its effectiveness will vary with the user's analysis and response abilities. If the optimization and risk management algorithms are further developed and equipped in the proposed model in near future, it will be very helpful for decision making for successful business management.

\section{Conclusions}

This study developed a simulation model that can dynamically forecast, control and monitor, and manage the five major economic risk factors of apartment development projects. Sales income and project costs can be adjusted within the variation ranges of the risk factors, to ensure project profitability. The model's effectiveness was verified through a case analysis as follows:

First, the simulation model easily and quickly calculated the variation range of the profit by analyzing the dynamic relationships of the risk factors. In the case project, simulations based on the initial values created during project preparation produced average, maximum, and minimum project profits of 6,737,158 USD, 200,255,758 USD, and $-82,461,955$ USD.

Second, this model produced the upper and lower control limits of each risk factor to achieve the targeted profit using the simulation results. In the case project, the management range of the unit sale price, land cost, and construction cost to achieve the target profit rate of 9.3-10\% was derived from $2,174-4,067 \mathrm{USD} / \mathrm{m}^{2}, 728-$ $1,526 \mathrm{USD} / \mathrm{m}^{2}$, and $787-1,140 \mathrm{USD} / \mathrm{m}^{2}$.

Third, the proposed dynamic model simulates the financial cost and project profit by adjusting the unit sale price when the low sales ratio occurs. The simulation results support the developer's decision making. In the case project, if the unit sale price is adjusted from $3090 \mathrm{USD} / \mathrm{m}^{2}$ to $2,960 \mathrm{USD} / \mathrm{m}^{2}$, the project profit is an average of $41,042,000$, up to $58,152,000$ USD and a minimum of 23,933,000 USD.

In this way, the model developed in this study is able to control project risk factors, and can easily and quickly simulate the economic impact of risk factors which change throughout the project. The simulation results can be used to analyze the economic feasibility of the project and develop a plan to reduce its economic loss, if necessary. It will also be used to develop optimization and risk management models in the future.

\section{Funding}

This work was supported by the National Research Foundation of Korea (NRF) grant funded by the Korea government (MOE) (No. 2017R1D1A1B04033761).

\section{Author contributions}

K. Lee and S. Kim were responsible for designing simulation model and developing related algorithm. S. Son and D. Kim was responsible for data collection and analysis for the case study and drafted the paper. K. Lee, S. Kim, and S. Son jointly performed the verification of the developed algorithm and the utility of the model.

\section{References}

Adair, A., McGreal, S., Smyth, A., Cooper, J., \& Ryley, T. (2000). House prices and accessibility: the testing of relationships within the Belfast urban area. Housing Studies, 15(5), 699716. https://doi.org/10.1080/02673030050134565

Albert, I., Grenier, E., Denis, J. B., \& Rousseau, J. (2008). Quantitative risk assessment from farm to fork and beyond: a global Bayesian approach concerning food-borne diseases. Risk Analysis: An International Journal, 28(2), 557-571. https://doi.org/10.1111/j.1539-6924.2008.01000.x

Al-Bahar, J. F., \& Crandall, K. C. (1990). Systematic risk management approach for construction projects. Journal of Construction Engineering and Management, 116(3), 533-546. https://doi.org/10.1061/(ASCE)0733-9364(1990)116:3(533)

Ball, M., Meen, G., \& Nygaard, C. (2010). Housing supply price elasticities revisited: evidence from international, national, local and company data. Journal of Housing Economics, 19(4), 255-268. https://doi.org/10.1016/j.jhe.2010.09.004

Bae, B. Y., Kim, K. R., Shin, D. w., \& Cha, H. S. (2017). Improvement of calculating method of the officially assessed individual house price of aged apartment remodelling reflecting feasibility analysis. Korea Journal of Construction Engineering and Management, 18(6), 89-97.

Caldera, A., \& Johansson, $\AA$. (2013). The price responsiveness of housing supply in OECD countries. Journal of Housing Economics, 22(3), 231-249.

https://doi.org/10.1016/j.jhe.2013.05.002

Choi, N. H. (2002). Spatial analysis of the location of new public office building for evaluating the locational feasibility. Chungbuk Research Institute, 13(1), 103-118.

Choi, M., Park, M., Lee, H. S., \& Hwang, S. (2017). Dynamic modeling for apartment brand management in the housing 
market. International Journal of Strategic Property Management, 21(4), 357-370.

https://doi.org/10.3846/1648715X.2017.1315347

Chen, H. L., O’Brien, W. J., \& Herbsman, Z. J. (2005). Assessing the accuracy of cash flow models: the significance of payment conditions. Journal of Construction Engineering and Management, 131(6), 669-676.

https://doi.org/10.1061/(ASCE)0733-9364(2005)131:6(669)

Chan, E. H., \& Au, M. C. (2009). Factors influencing building contractors' pricing for time-related risks in tenders. Journal of Construction Engineering and Management, 135(3), 135-145 https://doi.org/10.1061/(ASCE)0733-9364(2009)135:3(135)

Ferreira, F. A., \& Jalali, M. S. (2015). Identifying key determinants of housing sales and time-on-the-market (TOM) using fuzzy cognitive mapping. International Journal of Strategic Property Management, 19(3), 235-244.

https://doi.org/10.3846/1648715X.2015.1052587

Go, S. S., Hong, J. H., Song, H., \& Park, H. K. (2005). A study on the trend of apartment brand and the residents' preference. Architectural Institute of Korea, 25(1), 19-22.

Huh, Y. K., Hwang, B. G., \& Lee, J. S. (2012). Feasibility analysis model for developer-proposed housing projects in the republic of Korea. Journal of Civil Engineering and Management, 18(3), 345-355. https://doi.org/10.3846/13923730.2012.698911

Han, S. P., Jang, H. M., Lee, Y. S., \& Kim, J. J. (2007). Model for dynamics cost-benefit analysis with system dynamics. Journal of the Architectural Institute of Korea, 23(1), 163-171.

Isaac, S., \& Navon, R. (2009). Modeling building projects as a basis for change control. Automation in Construction, 18(5), 656-664. https://doi.org/10.1016/j.autcon.2009.01.001

Jeong, K. H. (2001). Building a process model for feasibility analysis in an apartment housing development (Master Degree Dissertation). Kyung Hee University.

Koo, S. M., \& Jung, M. W. (2007). A basic study on the current state and problems of feasibility study-focused on the evaluation criteria of the existing relative researches. Architectural Institute of Korea, 23(9), 79-88.

Kim, G. H. (2006). A study on the sensitivity analysis of the financial analysis item in apartment project. Korean Journal of Construction Engineering and Management, 7(1), 100-109.

Lee, Y. H., Lee, S. H., \& Kim, J. J. (2016). Development of the housing business model to minimize the fluctuation risk of the housing market. Journal of the Korea Academia-Industrial Cooperation Society, 17(10), 635-646. https://doi.org/10.5762/KAIS.2016.17.10.635

Li, Y., \& Liao, X. (2007). Decision support for risk analysis on dynamic alliance. Decision Support Systems, 42(4), 2043-2059. https://doi.org/10.1016/j.dss.2004.11.008

Michael, B., Vicky, S., \& Michael, S. (2002). Residential real estate prices: a room with a view. Journal of Real Estate Research, 23(1-2), 129-138.

Mills, A. (2001). A systematic approach to risk management for construction. Structural Survey, 19(5), 245-252. https://doi.org/10.1108/02630800110412615

Nasirzadeh, F., Afshar, A., Khanzadi, M., \& Howick, S. (2008). Integrating system dynamics and fuzzy logic modelling for construction risk management. Construction Management and Economics, 26(11), 1197-1212. https://doi.org/10.1080/01446190802459924

Park, J. Y. (2018). A system development for risk management of apartment building projects using system dynamics ( $\mathrm{PhD}$ thesis). Kyunggido: Kyunghee University.

Park, J. B., Kwon, K. B., Cho, Y., \& Paek, J. H. (2008). Feasibility analysis model study of realestate development-focused on construction project development of apartment and stores. Journal of the Architectural Institute of Korea, 24(3), 179-186.

Park, M., Chu, Y., Lee, H. S., \& Kim, W. (2009). Evaluation methods for construction projects. Journal of Civil Engineering and Management, 15(4), 349-359.

https://doi.org/10.3846/1392-3730.2009.15.349-359

Park, H. S., Sun, S. L., \& Kim, J. J. (2006). A study of the influential factors on customer-based apartment brand equity. Journal of the Architectural Institute of Korea, 22(7), 83-90.

Rachmawati, F., Soemitro, R. A. A., Adi, T. J. W., \& Susilawati, C. (2018). Critical success factor for partnership in low-cost apartments project: Indonesia perspective. Pacific Rim Property Research Journal, 24(2), 149-160.

https://doi.org/10.1080/14445921.2018.1461769

Schniederjans, M. J., Hoffman, J. J., \& Sirmans, G. S. (1995). Using goal programming and the analytic hierarchy process in house selection. Journal of Real Estate Finance and Economics, 11(2), 167-176. https://doi.org/10.1007/BF01098660

Schieg, M. (2008). Strategies for avoiding asymmetric information in construction project management. Journal of Business Economics and Management, 9(1), 47-51. https://doi.org/10.3846/1611-1699.2008.9.47-51

Shi Ming, Y., \& Chee Hian, C. (2005). Obstruction of view and its impact on residential apartment prices. Pacific Rim Property Research Journal, 11(3), 299-315. https://doi.org/10.1080/14445921.2005.11104189

Seo, J. K. (2016). Housing policy and urban sustainable development: evaluating the process of high-rise apartment development in Korea. Urban Policy and Research, 34(4), 330-342. https://doi.org/10.1080/08111146.2015.1118373

Tan, Y., Shen, L., \& Langston, C. (2010). Contractors' competition strategies in bidding: Hong Kong study. Journal of Construction Engineering and Management, 136(10), 1069-1077. https://doi.org/10.1061/(ASCE)CO.1943-7862.0000219

Warszawski, A. (2003). Parametric analysis of the financing cost in a building project. Construction Management and Economics, 21(5), 447-459.

https://doi.org/10.1080/0144619032000049638

Won, I. W. (2014). An investment risk management model of apartment building projects using system dynamics techniques (PhD thesis). Kyunggido: Kyunghee University.

Woo, K. M., \& Lee, H. K. (2005). A study on setting up the profitability-forecasting model of apartment reconstruction projects. Journal of the Architectural Institute of Korea, 21(9), 189-196.

Yoon, S. C., Yun, S. H., \& Paek, J. H. (2006). Forecasting cash flow by considering risk factors in the real estate development project. Journal of the Architectural Institute of Korea, 22(12), 165-172.

Yuan, H. P., Shen, L. Y., Hao, J. J., \& Lu, W. S. (2011). A model for cost-benefit analysis of construction and demolition waste management throughout the waste chain. Resources, Conservation and Recycling, 55(6), 604-612. https://doi.org/10.1016/j.resconrec.2010.06.004

Zavadskas, E. K., Turskis, Z., \& Tamošaitiene, J. (2010). Risk assessment of construction projects. Journal of Civil Engineering and Management, 16(1), 33-46.

https://doi.org/10.3846/jcem.2010.03 


\section{Notations}

Variables and functions

$P_{\text {project }}$ - Project profit (USD)

$S_{\text {total }}$ - Total sale income (USD)

$U P_{\text {type }_{i}}$ - Unit sale price (USD $\left./ \mathrm{m}^{2}\right)$

$U A_{\text {type }_{i}}$ - Sale area of each unit $\left(\mathrm{m}^{2}\right)$

$N_{i}$ - Number of units (EA)

$f\left(x_{i j}\right)$ - Sales ratio $(\%)$

$R_{\text {type }_{i}}$ - Total sales ratio (\%)

$C_{\text {total }}$ - Total project cost (USD)

$C C_{j}$ - Construction cost (USD)

$C L_{j}$ - Land cost (USD)

$C E_{j}$ - Other expense (USD)

$C_{\text {dire }_{j}}$ - Direct construction cost (USD)

$C_{i n d i_{j}}$ - Indirect construction cost (USD)

$P L_{i}$ - Land cost per each lot (USD $\left./ \mathrm{m}^{2}\right)$

$A L_{i}$ - Land area per each lot $\left(\mathrm{m}^{2}\right)$

$R L_{j}$ - Monthly land cost ratios (\%)

$C_{o s_{j}}$ - Outsourcing service cost (USD)

$E_{p s_{j}}$ - Sale expense (USD)

$E_{o t_{j}}$ - The other expense (USD)

$C_{F}$ - Total financial cost (USD)

$k$ - Deposit and loan interest rates (\%)

$F I_{j}$ - Monthly financial income (USD)

$F C_{j}$ - Monthly financial cost (USD)

$i$ - Number of unit types (Constant)

$j$ - The number of months from project commencement

to completion (constant) 